MedieKultur | Journal of media and communication research | ISSN 1901-9726

Article - Open issue

\title{
Creating opportunities for digital engagement and participation
}

\author{
Maja Nordtug
}

MedieKultur 2020, 68, 25-41

Published by SMID | Society of Media researchers In Denmark | www.smid.dk The online version of this text can be found open access at www.mediekultur.dk

\begin{abstract}
Worldwide, digital media are used by laypersons for health-related purposes. Laypersons' engagement and participation on the subject of health is the focus of this article, in which I explore how digital media create opportunities for laypersons to engage with information and participate on a health topic which has been subjected to controversy, namely HPV vaccination. The analysis is based on an inductive multidisciplinary literature review of research on digital media and HPV vaccination. In the analysis, I apply Corner's (2011) understanding of engagement and Kelty and colleagues' (2015) seven dimensions of participation. I find two kinds of engagement, namely using digital media as information sources and interpersonal communication, that both only satisfies few dimensions of participation. I argue that broader participation might be unachievable on health subjects such as vaccination and other subjects that require a high degree of expertise to understand. Due to this, laypersons cannot necessarily engage or participate further.
\end{abstract}

\section{Keywords}

Digital media; social media; participation; engagement; health; HPV vaccination 


\section{Introduction: Laypersons' digital engagement and participation}

A prevalent use of the internet for health-related purposes has been suggested across different nations, pointing to digital media's importance regarding laypersons' health (Kontos et al., 2014; Kummervold et al., 2008). Deborah Lupton points to an "enthusiasm for lay people to engage with digital technologies as part of taking responsibility for their health status and healthcare" (Lupton, 2013, p. 6). In this article, I focus on that engagement as well as the participatory dimensions of this engagement when exploring how digital media create opportunities for laypersons to engage with information and participate on a health topic subjected to controversy around the world, namely that of vaccination against human papillomavirus (HPV). HPV is a sexually transmitted infection associated with diseases such as cervical cancer, anal cancer, and genital warts (Seth et al., 2009). Since 2006, vaccines against different HPV types have been licensed in over 100 countries aiming to prevent HPV-associated diseases such as the abovementioned (Markowitz et al., 2012). After the licensing of the HPV vaccines, the vaccines have been debated and disputed worldwide. The debates about HPV vaccination have partially addressed the concerns that the vaccines have induced regarding promiscuity (Warner et al., 2017), early, risky, or unacceptable sexual behavior (Marchand et al., 2013), affordability (Li, 2011), fear of needles (Clark et al., 2016), and potential side effects (Burke et al., 2010; Newman et al., 2013). To explore how laypersons are able to participate and engage with information on this vaccine, I seek to answer the following question: How do digital media create opportunities for laypersons to engage with information and participate on HPV vaccination?

Digital media will be understood in this article as a "catch phrase for an ensemble of technologies" of which some are "born" digital and others can be made digital (Drotner, 2008, p. 16). I explore the opportunities digital media create by reviewing the research literature on the topic and analyzing the literature review in terms of engagement and participation. This is done to get an understanding of the opportunities created for laypersons across studies, countries, and research disciplines. By laypersons, I refer here to individuals who, though they might have some knowledge of vaccines, do not "have expertise that involves understanding of the technical complexities of disease, disease causation, clinical procedures and so on" (Nettleton, 2013, p. 36). Thus, laypersons - who are, by definition, non-experts - will not have the same expertise and knowledge about HPV vaccination and the concerns about them as actual vaccine experts.

Engagement is a term used in this article to conceptualize laypersons' relation to media. The term engagement is understood in terms of John Corner's definition of the concept as:

the selective and more oriented kinds of attention that some exposure is given. This attention involves a degree of cognitive focus that simply will not, and cannot, be given in many of the circumstantial settings in which media products and performances are encountered during everyday routine. It may be accidentally initiated but it is principally purposive, a 
motivated selection from the range of possible connections with mediation. (Corner, 2011, p. 91).

As such, engagement can be understood as purposive and selective attention that involves laypersons to focus cognitively. I apply engagement in this article to point out and specify laypersons' use of digital media concerning HPV vaccination and how different kinds of engagement satisfies different dimensions of participation. In this article, engagement is also understood as the intensive forms of engagement referred to by Corner as involvement. It is not, however, understood merely in terms of exposure and "glancing" contact is not included (Corner, 2011).

The participatory opportunities of these engagements are analyzed in terms of Christopher Kelty and colleagues' (2015) presentation of seven dimensions of participation. In healthcare, participation is increasingly understood as an important concept (Stage et al., 2015). However, according to Kelty and colleagues (2015), the concept of participation is understood very broadly and is heterogeneous in its definition. This is based on a diverse history, as several disciplines have sought to capture what participation means. Amongst the fields are citizen participation, worker participation and participatory democracy (Kelty et al., 2015).

Based on an extensive literature review of participation research, Kelty and colleagues present seven dimensions of participation that can help show the multi-dimensionality of the concept. The seven dimensions are as follows:

1. The educative dividend of participation.

2. Access to decision-making and goal setting in addition to task-completion.

3. The control or ownership of resources produced by participation.

4. Its voluntary character and the capacity for exit.

5. The effectiveness of voice.

6. The use of metrics for understanding or evaluating participation.

7. The collective, affective experience of participation

(Kelty et al., 2015, p. 2).

First, Kelty and colleagues present that the educative dividend of participation is a dual dimension, referring to both civic virtue and new knowledge, such as developing new approaches and skills. The second dimension refers to the possibility for participants to be involved in setting goals, making decisions, and task completion. The third dimension refers to the ability for participants to own or use the resources they have produced. Fourth, the ability to exit a participatory activity without detrimental consequences. The fifth dimension refers to the ability to voice through acts such as complaint, discussion and giving feedback. The sixth dimension refers to the creation of metrics "that either model the outcome of increased participation, or allow an individual to monitor [...] his or her contribution to something, and its effects" (Kelty et al., 2015, p. 10). The seventh 
dimension points to the ability for participants to have a collective experience of participation.

The empirical data used to explore the opportunities created is research papers on digital media and HPV vaccination from a range of different research fields. The literature search was conducted inductively and the theoretical framework was found after the literature search. The concepts of engagement and participation were found to be useful to support the findings of the literature search. The concepts were thus not included in the literature search but were applied subsequently. By reviewing the research, I was able to detect tendencies across research fields and countries and, thereby, get a broader understanding of the opportunities digital media create for laypersons.

\section{Methodology}

To get an overview of the research on digital media and HPV vaccination, I conducted a review of research within three fields: social sciences, health studies and the humanities. I conducted a systematic literature search through the following five databases: Academic Search Premier, Communication Source, PubMed, Web of Science and Scopus. These five databases do not represent a complete list of the research within the different fields. However, combined they give profound insight into the different research that has been conducted, as their academic foci vary. Conducting a review based on a wide range of search keywords across disciplines, as well as a diverse range of databases, this article thus presents a comprehensive insight into how digital media create opportunities for laypersons to engage with information and participate on the subject of HPV vaccines across academia.

Searching through the databases, three groups of search keywords were identified. These three groups are digital media, vaccination, and HPV, respectively. The keywords within the three groups are as follows (keywords ending with an asterix mark open-ended search terms):

1) Digital media: "digital media", internet, digital, "new media", web*, "social media", Facebook, Instagram, Twitter, Google, MySpace, blog*, vlog*, online*, "text messag*", texting, "mobile phone", smartphone*, "mobile app*”, "social network*”, email*, e-mail", computer*, YouTube, SNS", and "Internet Publishing and Broadcasting and Web Search Portals".

2) Vaccination: vaccin* and immunizati*.

3) HPV: HPV*, "Human papillomavir*”, Gardasil, "Human papilloma vir*”, Cervarix, Papillomavir*, and "Merck \& Co. Inc.".

The above search keywords represent the full amount of search keywords included in the literature search. Choosing the search keywords was carried out in several steps as 
I initiated the search with fewer search keywords. However, going through the material from the initial search in the databases, further search keywords appeared resulting in the presented keywords. Using this methodology for choosing the search keywords resulted in a thorough search through the literature.

All search terms from the three keyword groups were employed in a final systematic search in the five previously mentioned databases on January 4th, 2018. The searches prompted a total of 3,075 results. Having removed duplicates, 1,784 unique articles remained. To assess which articles should be included in this study, all titles and abstracts were read. Whether the articles were deemed relevant for this study depended on three selection criteria. First, the literature had to treat digital media, vaccination, and HPV in combination. Second, digital media had to be one of the main foci in the articles. Third, the literature had to place its focus on how laypersons use digital media in relation to HPV vaccination.

In this article, I preliminarily coded the 1,784 unique entities inductively for relevance by evaluating whether the entities met the criteria put forward previously. Media researcher Sara Mosberg Iversen explains how the purpose of the first coding cycle is to form a clear picture of what is going on in each text as well as in the material as a whole (2017, p. 156). This primary coding was conducted by hand and resulted in 52 entities assessed as relevant. These 52 articles were all read to establish whether they still met the sorting criteria.

\section{Establishing themes using NVivo}

Establishing themes in a large material of article entities can be assisted by using a software suitable for that purpose. To sort the titles and abstracts of the 52 articles prompted by my initial coding, I used the computer assisted qualitative data analysis software NVivo which offers computer-assisted coding opportunities (Iversen, 2017). For this study, employing codes enables assigning meaning to the entities made up by the articles' titles and abstracts. NVivo enabled me to assign an entity of article sets consisting of a title and an abstract, one or more codes that attributed meaning to each entity. The codes were assigned exploratively using the NVivo software which offers an increased overview (Iversen, 2017). I added codes (nodes) to the 52 entities (Miles et al., 2014). Fourteen of the 52 read articles were deemed relevant for this analysis, as these articles met the three selection criteria. Iversen (2017) presents that the second coding cycle is conducted in order to gather the descriptive codes into analytical themes. Based on these codes, I then found the two overall kinds of use which, in this article, are understood in terms of engagement and participation.

In the following analysis, I present the different kinds of engagement and dimensions of participation. The fourteen articles reviewed are presented in Table 1 at the end of the analysis. 
Article: Creating opportunities for digital engagement and participation

\section{Analysis}

From the literature, I identified two overall kinds of engagement: using digital media as information sources and interpersonal communication. In the following analysis, I will present these kinds of engagement and analyze whether these kinds of engagement can be ascribed one or more of Kelty and colleagues' (2015) seven dimensions. The two kinds of engagement are first analyzed in terms of engagement (Corner, 2011). Subsequently, the dimensions of participation are analyzed for each kind of engagement.

\section{Using digital media as information sources}

The first kind of engagement identified in the literature is the ability for laypersons to approach information on HPV vaccination digitally and search for information digitally without producing an articulated output. As such, digital media create opportunities for laypersons to use digital media as information sources. This involves not merely exposure to information about HPV vaccination but, following the definition put forward by Corner (2011), involves a cognitive, purposive focus. In the literature, this kind of engagement points to three overall findings.

First, laypersons search for and go to the internet for information on HPV vaccination rather independent of seasons and media coverage, though the internet search activity may increase due to media coverage on the vaccines (Bragazzi et al., 2017; Eberth et al., 2014; Kalichman \& Kegler, 2015). Digital media thus create opportunities for laypersons to use digital media as information sources continually.

Second, laypersons have different preferences when it comes to using digital media as information sources. In two studies conducted in 2007 and 2010 by Annie-Laurie McRee and colleagues (2012), the authors find that parents in North Carolina highly prefer the internet in order to seek information about HPV vaccination. Moreover, Dionne P. Stephens and Tami L. Thomas (2014) find that Hispanic women in the United States would turn to the internet to learn about HPV vaccination prior to turning to family members and healthcare providers. The women report that they use the internet for convenience, easy accessibility as well as concerns about confidentiality. A study by Jessica Hughes and colleagues (2009) also find that the internet is amongst the favored potential sources for future information on HPV vaccination among caregivers of adolescent girls in North Carolina. Moreover, Hughes and colleagues find that caregivers with a higher education are more likely to have heard about the vaccine through the internet. Further, these caregivers are more likely to cite the internet as a potential source of information about vaccination than people with a lower level of education. Nevertheless, different from Stephens and Thomas' (2014) study, the caregivers in Hughes and colleagues' (2009) study favor health care providers for information on HPV vaccination prior to the internet. This shows that though opportunities for laypersons to engage with digital media are created, digital media are not necessarily their only source of information. Digital media create 
these opportunities for engagement not only through access, but also through factors such as convenience and concerns about confidentiality (Stephens \& Thomas, 2014).

Third, using digital media as an information source seems to cause a complex decision-making process, and the created opportunities for engagement may be of importance regarding laypersons' decisions. In a study on French mothers and HPV vaccination, Jeremy K. Ward and colleagues (2017) find that the internet often provides the mothers with important information on the vaccine. Furthermore, the internet makes the mothers think about safety issues. Nevertheless, different from studies such as those by McRee and colleagues (2012), Stephens and Thomas (2014), and Hughes and colleagues (2009), the mothers who participated in Ward and colleagues' (2017) study report that information found on the internet is unreliable. The information found on the internet, according to the mothers in the study, "significantly affected decisions, introduced doubt, and prompted them to engage in further information-seeking" (Ward et al., 2017, p. 51). Engagement can then prompt and lead to a more intensive form of engagement (Corner, 2011). Furthermore, Kathy Livingston and colleagues find in a study on parents and caregivers' concerns about HPV vaccination that "[p]arents use many websites in their quest for health and vaccine information" (2014, p. 128). A similar finding can be found in a study by Rebecca Katherine Britt and colleagues (2014), who find some, though limited, support for an existing relationship between seeking information on HPV on social media sites such as Facebook, YouTube, and Twitter and attitudes and intention as well as subjective norms regarding HPV vaccines.

The analysis of the engagement shows that digital media create opportunities for laypersons to use digital media as information sources. From being a preferred source of information on HPV vaccination to being understood as an unreliable source causing a need to engage in further information-seeking, the way laypersons use digital media as information sources on HPV vaccination differs. Interestingly, while some authors do refer to specific internet use, such as which online settings people prefer (Stephens \& Thomas, 2014), other authors refer to the internet as a whole (Hughes et al., 2009; McRee et al., 2012). As such, these articles do not specify what is meant by the internet, and thus what aspects of the internet the laypersons engage with. Future research could advantageously specify what parts are being engaged with, and how these parts are engaged with and thus provide nuances to the field of research. If not, the internet as a term may be understood colloquially and from an emic perspective. This may leave out the nuances included in the concept of the internet which have expanded widely since the beginning of the 1990s (Brügger, 2013, 2016). Additionally, when referring to information sources, more research could specify the kinds of sources laypersons find reliable or unreliable. This is the case, as information sources found on digital media differ to the extent that they should rarely be understood as an unnuanced whole.

As to the participatory dimensions, the engagement of using digital media as information sources satisfies only a few of Kelty and colleagues' (2015) dimensions. 
First, the dimension of educative dividend is partially satisfied. Kelty and colleagues describe that there are two kinds of educative dividends: "cultivation of 'participatory' skills" and "marketable skills or life experience" (2015, p. 7). Using digital media as information sources creates educative dividends as laypersons can find knowledge about HPV vaccination and thus be educated on the matter. As such, this dimension is at least partially satisfied. However, as some laypersons might not have the sufficient knowledge to understand the information available on HPV vaccination, the mere presence of information does not guarantee an educative dividend. Pointing back to the definition put forward of a layperson (Nettleton, 2013), the lack of expertise may limit how much can be known by laypersons. Also, as Ward and colleagues (2017) point to in their study, the information found may not be reliable. Finding information that might be considered unreliable can thus appear contra productive in terms of educative dividends. Furthermore, using digital media as information sources does not necessarily cultivate participatory skills.

Second, in the cases described, Kelty and colleagues' (2015) dimension "exit" is satisfied. This is the case as many digital media sources are not contingent upon participation. Seeking information through digital media such as social media can cause a loss of access to information when exiting. However, finding information through searching on open browsers will not necessarily have consequences in terms of access if exiting that browser.

The five other dimensions of participation are not found in this kind of engagement, limiting this kind of engagement to only two dimensions of participation.

\section{Interpersonal communication}

Interpersonal communication is the second kind of engagement. This kind of engagement is found in articles focusing on laypersons' communication with, or to, others. This is engagement such as laypersons' comments, descriptions, discussions, debates, questions, and social media engagement. These kinds of communication all require a selective and purposive focus (Corner, 2011). Based on the literature, this kind of engagement can be analyzed as follows.

First, digital media create opportunities for laypersons to communicate interpersonally through engagements such as describing, debating, and asking questions on websites. Livingston and colleagues' (2014) study, which was also mentioned in this article's section on using digital media as information sources, focuses on how caregivers describe their concerns about HPV vaccination, and how they share and debate the issue on open internet websites. The themes discussed most frequently on these websites are safety and efficacy of the vaccine. Other main themes in the study are sexuality of child, age of immunization, gender issues and conflict on information-seeking (Livingston et al., 2014, p. 128). Studies on interpersonal communication also find that the internet is used as a space for debating and asking questions about HPV vaccination, and the internet is found to be "a cheap, accessible forum for users to relay and debate information from print 
media sources" (Eberth et al., 2014, p. 294). In a study of content on Japanese HPV vaccination websites, Tsuyoshi Okuhara and colleagues (2017) find that 50.7 percent of the materials they evaluated are negative towards HPV vaccination, 37.4 percent are positive, and 11.9 percent are neutral. The materials in the study with a negative sentiment is primarily produced by laypersons. As such, laypersons can produce content for others to read, and digital media create opportunities for laypersons to engage with others about HPV vaccination. Specifically, laypersons can communicate their sentiment to the vaccine.

Second, digital media create opportunities for laypersons to engage with social media. How they engage can, as also shown in Okuhara and colleagues' (2017) study, be a manifestation of their sentiment to the vaccine. The different studies on social media engagement such as tweets are not consistent regarding the polarization of sentiment. In an analysis on Dutch tweets on HPV vaccination, Rianne Kaptein and colleagues (2014) find that most of the users who tweet about HPV vaccination are positive about the vaccine and that the ones who post the majority of tweets are young girls getting the vaccine. Moreover, Kaptein and colleagues' analysis finds that "there are few in-depth discussions on Twitter" (2014, p. 478). In contrast to the findings of Kaptein and colleagues (2014), who find a majority of positive sentiment, Jessica Keim-Malpass and colleagues (2017) and Chi Y. Bahk and colleagues (2016) find that people primarily tweet negatively about HPV vaccination. In the study by Keim-Malpass and colleagues (2017), the authors find that lay consumers' sentiment on Twitter regarding HPV vaccination is 49.3 percent negative as opposed to 44.7 percent positive and 6 percent neutral. Furthermore, Keim-Malpass and colleagues find that the majority of the tweets are in fact written by lay consumers, and the posts are "sharing commentary about a media source" (2017, p. 316). Consistent with Keim-Malpass and colleagues' findings, in Bahk and colleagues' (2016) study, the authors find that the sentiment toward HPV vaccination on Twitter is predominantly negative. Bahk and colleagues study Twitter responses to a television show on December 4th, 2013, titled "HPV Vaccine Controversy". The sentiment towards HPV vaccination is shown to be negative both prior to and after the television show, though the authors show a decrease in negative sentiment during the show. In a study on YouTube (Basch et al., 2016), sentiment is also explored. Corey $\mathrm{H}$. Basch and colleagues (2016) find that regarding YouTube videos related to HPV, 42.9 percent of consumer videos about HPV are either entirely or partially about vaccination. Whereas the videos partially about HPV vaccination are mostly neutral in Basch and colleagues' study (2016), the videos entirely about HPV vaccination are all discouraging.

Summing up, in the field of study, varied engagement by laypersons regarding interpersonal communication have been found. The different engagements show that digital media create opportunities for laypersons to engage in conversational activities such as information sharing, debates, asking questions about HPV vaccination, and social media 
engagement. These kinds of engagement may also include intensive forms of engagement (Corner, 2011).

Regarding the participatory dimensions, three of Kelty and colleagues' (2015) dimensions appear to be satisfied, namely "voice", "collective, affective, and communicative experience of participation", and "educative dividend".

First, in the presented articles, there is a clear voicing of opinions, and the laypersons from the different studies are clearly able to ask questions and debate and discuss what they find important. Kelty and colleagues' (2015) dimension of "voice" is thus satisfied. However, whether the voiced opinions are in fact heard is unclear. Though researchers present what laypersons voice to a certain extent, it is unclear to what extent the voices are heard, have influence or are acted upon. Due to this, laypersons cannot model the outcome or model the effect of their participation, thus not satisfying Kelty and colleagues' dimension of metrics of participation. Moreover, their interactions, whether they be asking questions or tweeting, are not something the laypersons can be sure to be in control over afterwards. As such, they cannot be sure to exit the places where they interacted without losing control of the content (Kelty et al., 2015).

Second, the interpersonal communication shown points to digital media creating opportunities for "Collective, Affective, and Communicative Experience of Participation" (Kelty et al., 2015, p. 10). This is the case as laypersons can communicate with each other, which has the opportunity to create an affective tie. As shown in Kaptein and colleagues' (2014) study, however, though the opportunity is created, laypersons may not create these ties.

Third, educative dividends are also made possible. Laypersons may, for instance, get answers to their questions and thereby be educated on the topic (Kelty et al., 2015). However, as was also the case regarding the participatory dimensions of using digital media as information sources, the information laypersons receive may be considered unreliable. Nevertheless, laypersons may also learn how to use the different platforms and thereby cultivate their participatory skills (Kalichman \& Kegler, 2015).

The focus in many studies has, at least partially, explored the sentiment expressed on different sites. Whereas some studies show that the main sentiment towards HPV vaccination is negative, others show the opposite. This suggests that the results on this subject will vary according to factors such as methodology, point in time, and geography, and thus depend on the situation in question. From the reviewed articles, it appears studies on how laypersons engage with other major sites such as Facebook and Instagram have not been explored to the same extent as Twitter and YouTube.

Though some of the results are partially or completely contradictory, it is striking that the focus of these studies has been rather similar. In the next section, I will address the focus and aim of these different articles and discuss the implication this aim has on the understanding of how laypersons are situated in terms of engagement and participation. 


\begin{tabular}{|c|c|c|}
\hline Author (year) & $\begin{array}{l}\text { Country or source/platform and sample year } \\
\text { (if provided) relevant for review }\end{array}$ & Engagement present \\
\hline $\begin{array}{l}\text { Kalichman \& } \\
\text { Kegler (2015) }\end{array}$ & $\begin{array}{l}\text { American Google Correlate and Google Insight (now } \\
\text { Google Trends) data from } 2010 .\end{array}$ & $\begin{array}{l}\text { Using digital media as } \\
\text { information sources }\end{array}$ \\
\hline $\begin{array}{l}\text { Eberth et al. } \\
(2014)\end{array}$ & $\begin{array}{l}\text { Monthly event reports from VAERS, monthly media } \\
\text { reports from top-circulating US newspapers, and measures } \\
\text { from Google Insights (now Google Trends) from June } 2006 \\
\text { to December } 2008 .\end{array}$ & $\begin{array}{l}\text { Using digital media as } \\
\text { information sources }\end{array}$ \\
\hline $\begin{array}{l}\text { Bragazzi et al. } \\
(2017)\end{array}$ & $\begin{array}{l}\text { Google Trends query on the interest in HPV vaccines car- } \\
\text { ried out from } 2006 \text { onwards. }\end{array}$ & $\begin{array}{l}\text { Using digital media as } \\
\text { information sources }\end{array}$ \\
\hline $\begin{array}{l}\text { McRee et al. } \\
\text { (2012) }\end{array}$ & $\begin{array}{l}\text { Studies carried out in USA in } 2007(n=773) \text { and } 2010(n= \\
\text { 115). }\end{array}$ & $\begin{array}{l}\text { Using digital media as } \\
\text { information sources }\end{array}$ \\
\hline $\begin{array}{l}\text { Stephens \& } \\
\text { Thomas (2014) }\end{array}$ & $\begin{array}{l}\text { Interviews with } 41 \text { Hispanic college women between } 18 \\
\text { and } 24 \text { years of age in USA. }\end{array}$ & $\begin{array}{l}\text { Using digital media as } \\
\text { information sources }\end{array}$ \\
\hline $\begin{array}{l}\text { Hughes et al. } \\
(2009)\end{array}$ & $\begin{array}{l}\text { Interviews with } 889 \text { caregivers of adolescent girls ages } 10 \\
\text { to } 18 \text { years living in North Carolina, USA between July and } \\
\text { October } 2007 .\end{array}$ & $\begin{array}{l}\text { Using digital media as } \\
\text { information sources }\end{array}$ \\
\hline $\begin{array}{l}\text { Ward et al. } \\
(2017)\end{array}$ & $\begin{array}{l}\text { Semi-structured interviews with } 19 \text { French mothers in } \\
\text { France. }\end{array}$ & $\begin{array}{l}\text { Using digital media as } \\
\text { information sources }\end{array}$ \\
\hline $\begin{array}{l}\text { Livingston et } \\
\text { al. (2014) }\end{array}$ & $\begin{array}{l}\text { Comments from } 21 \text { websites with information or news } \\
\text { about HPV or parent support. }\end{array}$ & $\begin{array}{l}\text { Using digital media as } \\
\text { information sources; } \\
\text { Interpersonal communi- } \\
\text { cation }\end{array}$ \\
\hline $\begin{array}{l}\text { Britt et al. } \\
(2014)\end{array}$ & $\begin{array}{l}174 \text { participants from an American university population } \\
\text { in 2012, USA. }\end{array}$ & $\begin{array}{l}\text { Using digital media as } \\
\text { information sources }\end{array}$ \\
\hline $\begin{array}{l}\text { Kaptein et al. } \\
(2014)\end{array}$ & $\begin{array}{l}\text { 12,639 Dutch-language tweets collected during March and } \\
\text { April } 2013 \text { on Twitter. }\end{array}$ & $\begin{array}{l}\text { Interpersonal communi- } \\
\text { cation }\end{array}$ \\
\hline $\begin{array}{l}\text { Bahk et al. } \\
\text { (2016) }\end{array}$ & $\begin{array}{l}\text { Online responses to two vaccination-related events, } \\
\text { including one event about HPV vaccination which } \\
\text { occurred on December 4th, 2013. Data is collected from } \\
\text { the web-based platform Vaccine Sentimeter. }\end{array}$ & $\begin{array}{l}\text { Interpersonal communi- } \\
\text { cation }\end{array}$ \\
\hline $\begin{array}{l}\text { Keim-Malpass } \\
\text { et al. (2017) }\end{array}$ & $\begin{array}{l}\text { Content and sentiment of 1,794 English-language tweets } \\
\text { collected over } 2 \text { weeks in June } 2015 \text { on Twitter. }\end{array}$ & $\begin{array}{l}\text { Interpersonal communi- } \\
\text { cation }\end{array}$ \\
\hline $\begin{array}{l}\text { Basch et al. } \\
(2018)\end{array}$ & $\begin{array}{l}\text { The } 35 \text { most popular English-language consumer videos on } \\
\text { HPV and the } 35 \text { most popular English-language profes- } \\
\text { sional videos on HPV on YouTube. }\end{array}$ & $\begin{array}{l}\text { Interpersonal communi- } \\
\text { cation }\end{array}$ \\
\hline $\begin{array}{l}\text { Okuhara et al. } \\
\text { (2017) }\end{array}$ & $\begin{array}{l}270 \text { Japanese-language websites found on October } 5 \text { th, } \\
2016 .\end{array}$ & $\begin{array}{l}\text { Interpersonal communi- } \\
\text { cation }\end{array}$ \\
\hline
\end{tabular}

Table 1: Overview of reviewed articles.

\section{Discussion}

The above analysis shows two ways digital media create opportunities for laypersons to engage with information on HPV vaccination. In the first kind, using digital media as 
information sources, only two of Kelty and colleagues' (2015) participatory dimensions are satisfied, namely "educative dividend" and "exit". In the second kind, interpersonal communication, three dimensions are satisfied, namely "voice", "collective, affective, and communicative experience of participation", and "educative dividend". Only pointing to two and three dimensions, neither kind of engagement thus seem to represent any broad kind of participation.

It is interesting to relate Nico Carpentier's $(2011,2015)$ understanding of participation to Kelty and colleagues' dimensions. This is the case as Carpentier, according to Kelty and colleagues, "is almost unique" for "his critical examination of participation and media" (2015, p. 1). Carpentier's understanding can therefore further the understanding of how laypersons are situated in terms of participation with media on this health topic. Carpentier distinguishes between minimalist and maximalist media participation, and understands minimalist media participation as a form in which "media professionals retain strong control over process and outcome, often restricting participation to mainly access and interaction" (2015, p. 19). On the contrary, maximalist media participation is understood as more balanced, "and attempts are made to maximize participation" (Carpentier, 2015, p. 19). If the presented articles were to be analyzed in terms of Carpentier's understanding of participation, it would be questionable whether the kinds of engagement could be understood in terms of participation at all. According to Carpentier's distinction between interaction and participation, it is questionable whether the opportunity to merely voice your opinion for instance qualifies as actual participation. To the extent that the concept of participation can be considered applicable to the kinds of engagement acted out by laypersons in the literature, the participatory practices may be considered minimalist in Carpentier's understanding of the term. As such, the created opportunities for participation can be understood as minimalist in Carpentier's $(2011,2015)$ understanding and narrow in Kelty and colleagues' (2015) understanding.

Broad or maximalist participation might, however, not be desired in this field of study. Though the results from the articles are not consistent throughout the field of study, many authors have a similar overall goal with their research: to express the importance of working towards a high HPV vaccine coverage rate. These authors thus point to how their study may contribute to a high coverage rate. As such, the goal is not necessarily to maximize participation or create further opportunities for participation. The goal of working towards a high vaccination uptake is expressed in three different ways.

First, some researchers express the goal of higher vaccination rates by identifying factors of value to the coverage rate. Amongst these researchers are Stephens and Thomas (2014) who identify who and what within Hispanic college women's social network influence their HPV vaccine decision-making process. Similarly, in Hughes and colleagues' (2009) study, the authors focus on variables that may strengthen communications about $H P V$ vaccination that will further increase HPV vaccine awareness levels amongst American caregivers of adolescent girls. Likewise, Bahk and colleagues (2016) assess a platform 
which monitors vaccination-related content. They argue that monitoring is essential "for public health professionals and policy makers to better understand and address vaccine hesitancy" (Bahk et al., 2016, p. 341), as this is a step leading to behavior change. Moreover, the intention with Keim-Malpass and colleagues' study is to be "hypothesis-generating for future social marketing interventions pertaining to the HPV vaccine" (2017, p. 318). Thus, the goal is to add to the knowledge on how to best raise vaccination coverage rates.

Second, other researchers point to how their findings may contribute to raising vaccination levels. Britt and colleagues (2014) explain that their results can have an impact on public health policy and intervention, and Kalichman and Kegler suggest how their findings "have important implications for vaccine promotion" (2015, p. 264). Likewise, Eberth and colleagues (2014) specify that their findings point to a "need for public health education efforts on the internet regarding potential vaccine side effects" (p. 294) as well as to the necessity of public health officials to "consider strategies for meaningful participation in Internet discussions" (p. 289). Equally, Basch and colleagues (2016) explain that governmental and non-governmental agencies' presence and popularity on social media sites may increase vaccination rates, as they point to these levels being too low. Similarly, Okuhara and colleagues present practice implications stating how to effectively "sway the anti-HPV vaccination sentiment" (2017, p. 411).

Finally, Bragazzi and colleagues point to the importance of "ensuring a high acceptance and coverage rate during vaccination campaigns" (2017, p. 464). McRee and colleagues (2012) argue that it is important that parents are able to "locate valid, clear, and complete online information about HPV and HPV vaccine" (p. 3760), which, according to the article's introduction, is the information "available from public agencies" (p. 3757) and typically not sites opposing HPV vaccination.

Though the authors may have had additional purposes with the articles, a common denominator is that they by some means work towards a high HPV vaccination rate. Thus, the goals are to find out how their research can help establish ways to make people choose to get vaccinated. As such, the researchers approach the subject top-down. They wish to (help those in power) create lines of force to make a population do what is considered the best behavior regarding their health: to get an HPV vaccine (Bröckling et al., 2011; Foucault \& Senellart, 2007). This specific behavior is regarded as the favorable one for the best of both the individual and the state (Foucault \& Senellart, 2007). Thus, it appears that when researchers try to contribute to higher vaccination rates, they are focusing on the subject from the approach of those in power. Consequently, it can be argued that broadening participation might not help raise vaccination rates.

However, it might be possible to have another approach to research on digital media and HPV vaccination. Contrary to the research working towards a high vaccination rate, Livingston and colleagues (2014) do not demonstrate this top-down approach. Rather, they argue that medical knowledge is socially constructed and, based on Latour, "the result of sociopolitical and economic forces which allow certain scientific ideas to advance 
or 'succeed' while causing other ideas, which may be just as accurate, to recede or 'fail'" (Livingston et al., 2014, p. 121). Moreover, Livingston and colleagues argue that the internet may be more inclusive concerning information on HPV vaccination than laypersons' health care providers. As such, in Livingston and colleagues' study, in which the authors aim to investigate the caregivers' concerns, the approach is rather bottom-up than topdown. This approach points to the opportunities to approach research on digital media and HPV vaccination differently. Furthermore, two of the studies are not explicit concerning their aim. In their paper, Kaptein and colleagues are not explicit as to why they find it important to get a "view of the social influence effect taking place during discussions via Twitter" (2014, p. 475). Likewise, Ward and colleagues (2017) are not explicit as to whether or not the aim of their research is to heighten vaccination rates. Not having higher vaccination rates as the primary purpose of research might then create opportunities to approach research on HPV vaccination and digital media differently, thereby possibly placing media not just as either creating opportunities for higher vaccination rates or being the hindrance thereof. This, however, is not the case in the majority of articles on how laypersons engage with digital media on the subject of HPV vaccination. In Carpentier's (2015) as well as Kelty and colleagues' (2015) terms, in the majority of the studies, attempts are not made to maximize or broaden participation.

The ideal of maximized or broad participation, however, might not be possible in this field. Though many laypersons do have physical access creating opportunities for engagement and dimensions of participation, the fact that they are not experts in the field can be a barrier to their ability to participate or engage more (Nettleton, 2013). The inability to participate in a broader sense, due to lack of expertise, is likely to recur not only in other health topics but also in a variety of other complex knowledge fields.

\section{Conclusion}

In this article, I analyze how digital media create opportunities for laypersons to engage with information and participate on HPV vaccination. The analysis is based on papers from a multidisciplinary review of research conducted on digital media and HPV vaccination across different countries. Corner's (2011) understanding of engagement and Kelty and colleagues' (2015) seven dimensions of participation are applied to the analysis to support the findings regarding the created opportunities for engagement and participation found in the review. I find two categories of engagement researched within the humanities, social studies and health studies: using digital media as information sources and interpersonal communication. Using digital media as information sources on HPV vaccination is continually possible for laypersons. However, there are differences in their preferences, and having the opportunity to use digital media as information sources may make decision-making more complex for laypersons. The studies focusing on interpersonal communication show that digital media create opportunities for laypersons to communi- 
cate through, for instance, commenting, describing, asking questions or communicating on social media. The two kinds of engagement found were analyzed in terms of the seven dimensions of participation presented by Kelty and colleagues (2015). The analysis showed that the engagement of using digital media as information sources at least partially satisfied two dimensions, namely "educative dividend" and the ability to "exit". The engagement of interpersonal communication satisfied three dimensions, namely that of "voice", "collective, affective, and communicative experience of participation" as well as "educative dividend". Only satisfying two and three dimensions, it is argued that neither of the two kinds of engagement represent opportunities for broad communication. However, it is argued that maximized or broader participation might not be possible for laypersons on certain health topics or other topics that require a higher level of expertise.

\section{References}

Bahk, C.Y., Cumming, M., Paushter, L., Madoff, L.C., Thomson, A., \& Brownstein, J. S. (2016). Publicly available online tool facilitates real-time monitoring of vaccine conversations and sentiments. Health Affairs, 35(2), 341-347. Retrieved July 1, 2020, from https://www.doi.org/10.1377/hlthaff.2015.1092.

Basch, C.H., Hillyer, G.C., Berdnik, A., \& Basch, C.E. (2016). YouTube videos related to human papillomavirus: The need for professional communication. International Journal of Adolescent Medicine and Health, 30(1), 20150122. Retrieved July 1, 2020, from https://www.doi.org/10.1515/ijamh-2015-0122.

Bragazzi, N.L., Barberis, I., Rosselli, R., Gianfredi, V., Nucci, D., Moretti, M., ... Martini, M. (2017). How often people google for vaccination: Qualitative and quantitative insights from a systematic search of the web-based activities using Google Trends. Human Vaccines and Immunotherapeutics, 13(2), 464-469. Retrieved July 1, 2020, from https://www.doi.org/10.1080/21645515.2017.1264742.

Britt, R.K., Hatten, K.N., \& Chappuis, S.O. (2014). Perceived behavioral control, intention to get vaccinated, and usage of online information about the human papillomavirus vaccine. Health Psychology and Behavioral Medicine, 2(1), 52-65. Retrieved July 1, 2020, from https://www.doi.org/10.1080/21642850.2 013.869175.

Brügger, N. (2013). Facebooks historie. Udviklingen af en tom struktur. In J.L. Jensen, \& J. Tække (Eds.), Facebook. Fra socialt netvark til metamedie (1st ed., pp. 17-44). Frederiksberg: Samfundslitteratur.

Brügger, N. (2016). Introduction: The web's first 25 years. New Media \& Society, 18(7), 1059-1065. Retrieved July 1, 2020, from https://www.doi.org/10.1177/1461444816643787.

Bröckling, U., Krasmann, S., \& Lemke, T. (Eds.). (2011). Governmentality. New York: Routledge.

Burke, S.C., Vail-Smith, K., White, D.M., Baker, E., \& Mitchell, T. (2010). Getting vaccinated against HPV: Attitudes, intentions and perceived barriers of female undergraduates. College Student Journal, 44(1), 55-63.

Carpentier, N. (2011). The Concept of Participation: If They Have Access and Interact, do They Really Participate? CM Komunikacija i mediji, 6(21), 13-36.

Carpentier, N. (2015). Differentiating between access, interaction and participation. Conjunctions. Transdisciplinary Journal of Cultural Participation, 2(2), 7-28. Retrieved July 1, 2020, from https://doi. org/10.7146/tjcp.v2i2.23117. 
Clark, S.J., Cowan, A.E., Filipp, S.L., Fisher, A.M., \& Stokley, S. (2016). Understanding non-completion of the human papillomavirus vaccine series: Parent-reported reasons for why adolescents might not receive additional doses, United States, 2012. Public Health Reports, 131(3), 390-395. Retrieved July 1, 2020, from https://doi.org/10.1177/003335491613100304.

Corner, J. (2011). Theorising Media: Power, Form and Subjectivity. Manchester: Manchester University Press.

Drotner, K. (2008). Informal learning and digital media: Perceptions, practices and perspectives. In K. Drotner, H.S. Jensen, \& K.C. Schrøder (Eds.), Informal Learning and Digital Media (pp. 10-28). Newscastle: Cambridge Scholars Publishing.

Eberth, J.M., Kline, K.N., Moskowitz, D.A., Montealegre, J.R., \& Scheurer, M.E. (2014). The role of media and the Internet on vaccine adverse event reporting: $A$ case study of human papillomavirus vaccination. Journal of Adolescent Health, 54(3), 289-295. Retrieved July 1, 2020, from https://www.doi.org/10.1016/j. jadohealth.2013.09.005.

Foucault, M., \& Senellart, M. (2007). Security, Territory, Population: Lectures at The College de France, 197778. Basingstoke: Palgrave Macmillan.

Hughes, J., Cates, J.R., Liddon, N., Smith, J.S., Gottlieb, S.L., \& Brewer, N.T. (2009). Disparities in how parents are learning about the human papillomavirus vaccine. Cancer Epidemiology, Biomarkers \& Prevention, 18(2), 363-372. Retrieved July 1, 2020, from https://www.doi.org/10.1158/1055-9965.epi-08-0418.

Iversen, S.M. (2017). Med NVivo som analyseparter. In K. I. Drotner, S. Mosberg (Ed.), Digitale metoder. At skabe, analysere og dele data (pp. 147-163). Frederiksberg: Samfundslitteratur.

Kalichman, S.C., \& Kegler, C. (2015). Vaccine-related internet search activity predicts H1N1 and HPV vaccine coverage: Implications for vaccine acceptance. Journal of Health Communication, 20(3), 259-265. Retrieved July 1, 2020, from https://www.doi.org/10.1080/10810730.2013.852274.

Kaptein, R., Boertjes, E., \& Langley, D. (2014). Analyzing discussions on Twitter: Case study on HPV vaccinations. In Lecture Notes in Computer Science (including subseries Lecture Notes in Artificial Intelligence and Lecture Notes in Bioinformatics) (Vol. 8416) (pp. 474-480).Retrieved August 24, 2020, from https:// link.springer.com/chapter/10.1007/978-3-319-06028-6_44.

Keim-Malpass, J., Mitchell, E.M., Sun, E., \& Kennedy, C. (2017). Using Twitter to understand public perceptions regarding the \# HPV vaccine: Opportunities for public health nurses to engage in social marketing. Public Health Nursing, 34(4), 316-323. Retrieved July 1, 2020, from https://www.doi.org/10.1111/ phn.12318.

Kelty, C., Panofsky, A., Currie, M., Crooks, R., Erickson, S., Garcia, P., ... Wood, S. (2015). Seven dimensions of contemporary participation disentangled. Journal of the Association for Information Science and Technology, 66(3), 474-488. Retrieved July 1, 2020, from https://www.doi.org/10.1002/asi.23202.

Kontos, E., Blake, K.D., Chou, W.-Y.S., \& Prestin, A. (2014). Predictors of eHealth usage: Insights on the digital divide from the health information national trends survey 2012. Journal of Medical Internet Research, 16(7), e172. Retrieved July 1, 2020, from https://www.doi.org/10.2196/jmir.3117.

Kummervold, P.E., Chronaki, C.E., Lausen, B., Prokosch, H.-U., Rasmussen, J., Santana, S., .. Wangberg, S.C. (2008). eHealth Trends in Europe 2005-2007: A Population-Based Survey. Journal of Medical Internet Research, 10(4), e42. Retrieved July 1, 2020, from https://www.doi.org/10.2196/jmir.1023.

$\mathrm{Li}, \mathrm{W}$. (2011). Issues surrounding HPV vaccine delivery in a multi-ethnic country in Asia: The physician's perspective. Journal of Community Health, 36(1), 14-22. Retrieved July 1, 2020, from https://www.doi. org/10.1007/s10900-010-9275-0.

Livingston, K., Sutherland, K.M., \& Sardi, L.M. (2014). Reject, delay, or consent? Parents' internet discussions of the HPV vaccine for children and implications for HPV vaccine uptake. Research in the Sociology of Health Care, 32, 117-139. Retrieved July 1, 2020, from https://doi.org/10.1108/S0275495920140000032018. 
Lupton, D. (2013). Digitized health promotion: Personal responsibility for health in the web 2.0 era. (Sydney Health \& Society Group Working Paper No. 5). Sydney Health \& Society Group.

Marchand, E., Glenn, B., \& Bastani, R. (2013). HPV vaccination and sexual behavior in a community college sample. Journal of Community Health, 38(6), 1010-1014. Retrieved July 1, 2020, from https://www.doi. org/10.1007/s10900-013-9710-0.

Markowitz, L.E., Tsu, V., Deeks, S. L., Cubie, H., Wang, S.A., Vicari, A.S., \& Brotherton, J.M.L. (2012). Human papillomavirus vaccine introduction - the first five years. Vaccine, 30, F139-F148. Retrieved July 1, 2020, from https://doi.org/10.1016/j.vaccine.2012.05.039.

McRee, A.L., Reiter, P.L., \& Brewer, N.T. (2012). Parents' Internet use for information about HPV vaccine. Vaccine, 30(25), 3757-3762. Retrieved July 1, 2020, from https://www.doi.org/10.1016/j.vaccine.2011.11.113.

Miles, M.B., Huberman, A.M., \& Saldaña, J. (2014). Qualitative Data Analysis (3rd ed.). London: Sage.

Nettleton, S. (2013). The Sociology of Health and Illness (3rd ed.). Cambridge: Polity Press.

Newman, P.A., Logie, C.H., Doukas, N., \& Asakura, K. (2013). HPV vaccine acceptability among men: A systematic review and meta-analysis. Sexually Transmitted Infections, 89(7), 568-574. Retrieved July 1, 2020, from https://www.doi.org/10.1136/sextrans-2012-050980.

Okuhara, T., Ishikawa, H., Okada, M., Kato, M., \& Kiuchi, T. (2017). Contents of Japanese pro- and antiHPV vaccination websites: A text mining analysis. Patient Education and Counseling, 101(3), 406-413. Retrieved July 1, 2020, from https://www.doi.org/10.1016/j.pec.2017.09.014.

Seth, P., Wingood, G.M., Robinson, L.S., \& DiClemente, R.J. (2009). Exposure to high-risk genital human papillomavirus and its association with risky sexual practices and laboratory-confirmed chlamydia among African-American women. Women's Health Issues, 19(5), 344-351. Retrieved July 1, 2020, from https://doi.org/10.1016/j.whi.2009.06.001.

Stage, C., Eriksson, B., \& Fabian, L. (2015). Introduction participation across institutional and disciplinary boundaries. Conjunctions. Transdisciplinary Journal of Cultural Participation, 2(2), 1-6. Retrieved July 1, 2020, from https://www.doi.org/10.7146/tjcp.v2i2.22913.

Stephens, D.P., \& Thomas, T.L. (2014). Social networks influence hispanic college women's HPV vaccine uptake decision-making processes. Women's Reproductive Health, 1(2), 120-137. Retrieved July 1, 2020, from https://www.doi.org/10.1080/23293691.2014.966034.

Ward, J.K., Crépin, L., Bauquier, C., Vergelys, C., Bocquier, A., Verger, P., \& Peretti-Watel, P. (2017). 'I don't know if I'm making the right decision': French mothers and HPV vaccination in a context of controversy. Health, Risk \& Society, 19(1/2), 38-57. Retrieved July 1, 2020, from https://www.doi.org/10.1080/13 698575.2017.1299856.

Warner, E., Fowler, B., Martel, L., \& Kepka, D. (2017). Improving HPV vaccination through a diverse multistate coalition. Journal of Community Health, 42(5), 911-920. Retrieved July 1, 2020, from https://www. doi.org/10.1007/s10900-017-0334-7.

Maja Nordtug

PhD student

Department for the Study of Culture

University of Southern Denmark

majan@sdu.dk 